\title{
ELECCIONES A LA KNESSET DE ISRAEL
}

El cuerpo electoral istaelí fue convocado a las urnas el día 30 de junio de 1981 para renovar la Knesset de su país al ser decretada la disolución de la anterior el 10 de febrero de este mismo año.

La Knesset o Parlamento unicameral israelí es elegida por todos los ciudadanos del Estado de Israel mayores de dieciocho años que no hayan sido privados del derecho al voto. La Knesset se compone de 120 diputados y su legislatura dura cuatro años.

El sistema de elección de los miembros de la Knesset es proporcional sobre la base de considerar al territorio del Estado como un distrito electoral único a los efectos de distribuir los escaños entre los totales obtenidos por cada partido. El elector vota a una lista específica de candidatos, una lista de un partido. La distribución de los escaños se realiza, según el método D'Hondt de la media más elevada, entre todas las listas que hayan obtenido al menos un 1 por 100 de los votos emitidos. Dentro de cada lísta, la adjudicación de los escaños a los candidatos se lleva a cabo según el orden de aparición en la lista.

Muy a pesar de los resultados de los sondeos de opinión preelectorales, y en contra del pronóstico de la mayoría de los observadores políticos, Menahem Beguin, primer ministro israelí en la anterior legislatura, será llamado a formar gobierno por encargo del presidente de la República, Isaac Navon, tras unas elecciones en las que el Likud (partido de Beguin) ha visto ensombrecida su victoria por el resurgir del primer partido de la oposición parlamentaria, el Maarakh (laborista), de Simon Peres, que, habiéndose escrutado el 50 por 100 de los sufragios emitidos, marchaba aún por delante de la coalición conservadora Likud. En efecto, esta situación se daba cuando aún estaba por escrutar el voto del Ejército, tradicionalmente inclinado hacia posiciones conservadoras.

En las elecciones de 1977 el Ejército dio mayoritariamente su voto al Likud (44 por 100) frente a sus oponentes laboristas (22 por 100) y del Dash (26 por $100)$. En esta ocasión, en las elecciones que estamos analizando, el voto militar ha vuelto a recaer sobre el Likud ( 45 por 100 ); un reducido sector se muestra partidario de la formación ultraderechista Tehiya (6 por 100) y los partidarios de Peres en el Ejército aumentan sensiblemente sus porcentajes ( 35 por 100) ${ }^{1}$.

${ }^{1}$ Datos obtenidos de Le Monde Diplomatique, agosto 1981. 
Ofrezco a continuación un cuadro con los resultados de las elecciones.

\begin{tabular}{|c|c|c|c|c|c|}
\hline & $\begin{array}{c}\mathrm{N} . \mathbf{o}^{\mathrm{de}} \\
\text { candidatos } \\
\text { presentados }\end{array}$ & $\begin{array}{c}\text { Votos } \\
\text { obtenidos }\end{array}$ & $\%$ & $\begin{array}{c}\text { Escaños } \\
\text { obtenidos }\end{array}$ & $\begin{array}{c}\text { Anterior } \\
\text { legislatura }\end{array}$ \\
\hline Likud $^{1} \ldots \ldots \ldots \ldots \ldots$ & 120 & 718.941 & 37,11 & 48 & 40 \\
\hline $\begin{array}{c}\text { Maarakh }^{2} \\
\text { (Partido }\end{array}$ & 120 & 708.536 & 36,57 & 47 & 33 \\
\hline Partido Nacional Religioso. & 104 & 95.232 & 4,92 & 6 & 12 \\
\hline Agudat Israel $^{3} \ldots \ldots \ldots$ & 93 & 72.312 & 3,73 & 4 & 4 \\
\hline \\
\hline $\begin{array}{l}\text { la Paz y la Igualdad ... } \\
\text { (Comunista) }\end{array}$ & 120 & 64.918 & 3,35 & 4 & 5 \\
\hline \multirow{5}{*}{ 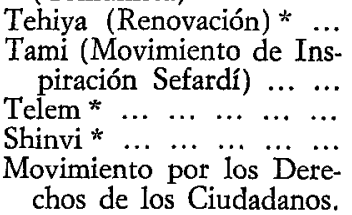 } & 120 & 44.700 & 2,31 & 3 & 2 \\
\hline & 41 & 44.466 & 2,30 & 3 & - \\
\hline & 115 & 30.600 & 1,58 & 2 & 4 \\
\hline & 120 & 29.837 & 1,54 & 2 & 5 \\
\hline & 119 & 27.921 & 1,44 & 1 & 1 \\
\hline
\end{tabular}

1 Coalición nacionalista formada por el Partido Herud de M. Beguin y el Partido Liberal.

2 Junto con el MAPAM (Izquierda Laborista).

3 Partido ultraortodoxo no sionista.

* Partidos formados durante la anterior Knesset.

FUENTE: Secretaría General de la Knesset de Israel.

Fernando Oltero Butler 


\section{LAS ELECCIONES AL DAIL IRLANDES}

Como consecuencia de la convocatoria de elecciones anticipadas por decisión del primer ministro saliente, Charles Haughey, del partido Fianna Fail (moderado), el día 11 de junio de 1981 los electores irlandeses acudieron a las urnas para renovar los escaños del Dail irlandés.

Haughey, que ya gozaba de la tranquilidad que proporciona el hecho de estar respaldado por una mayoría de 18 diputados en el Dail anterior, quiso asegurarse una mayoría aún más amplia para llevar a cabo el desarrollo de su programa político.

Pero aunque los resultados definitivos de los comicios arrojaron un saldo favorable al Fianna Fail (partido gobernante hasta estas elecciones), la repetición ${ }^{1}$ del pacto de gobierno entre el Fine Gael y el Labour Party ha dado como resultado la elección, para el cargo de primer ministro de la República de Irlanda, del líder del Fine Gael (centrista) Garret Fitzgerald 2 .

Además, el Fine Gael - principal partido de la oposición en là legislatura anterior- aumenta sensiblemente en número de diputados (45 en la anterior legislatura).

Pero el dato más significativo de las pasadas elecciones ha sido el apoyo concedido por los electores irlandeses a la causa de sus hermanos del Ulster. De esta manera, dos de los activistas del Irish Republican Army (I.R.A) encarcelados en la prisión de Maze (Ulster) consiguieron sendos escaños por las circunscripciones electorales de Cavan-Monagan y Louth, respectivamente.

1 Entre los años 1973 y 1977, Irlanda fue gobernada por la coalición Fine Gael-Labour.

2 Ministro de Exteriores en el gobierno de coalición de 1973 a 1977. 
CUADRO 1

DISTRIBUCION DE LOS ESCAÑOS DEL DAIL TRAS LAS ELECCIONES

\begin{tabular}{|c|c|}
\hline & Escaños \\
\hline 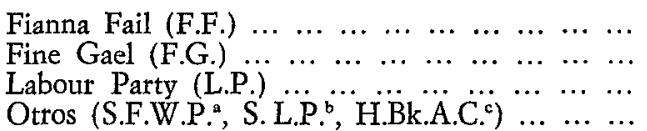 & $\begin{array}{r}78 \\
65 \\
15 \\
8\end{array}$ \\
\hline
\end{tabular}

a S.F.W.P.: Sinn Fein the Workers Party.

b S.L.P.: Socialist Labour Party.

c H.Bk.A.C.: H. Block Armagh Committee.

Utilizando datos extraídos del prestigioso diario londinense The Times ofrezco a continuación la distribución de los escaños por formaciones políticas y por circunscripciones electorales.

CUADRO 2

DISTRIBUCION DE LOS ESCAÑOS POR CIRCUNSCRIPCIONES ELECTORALES

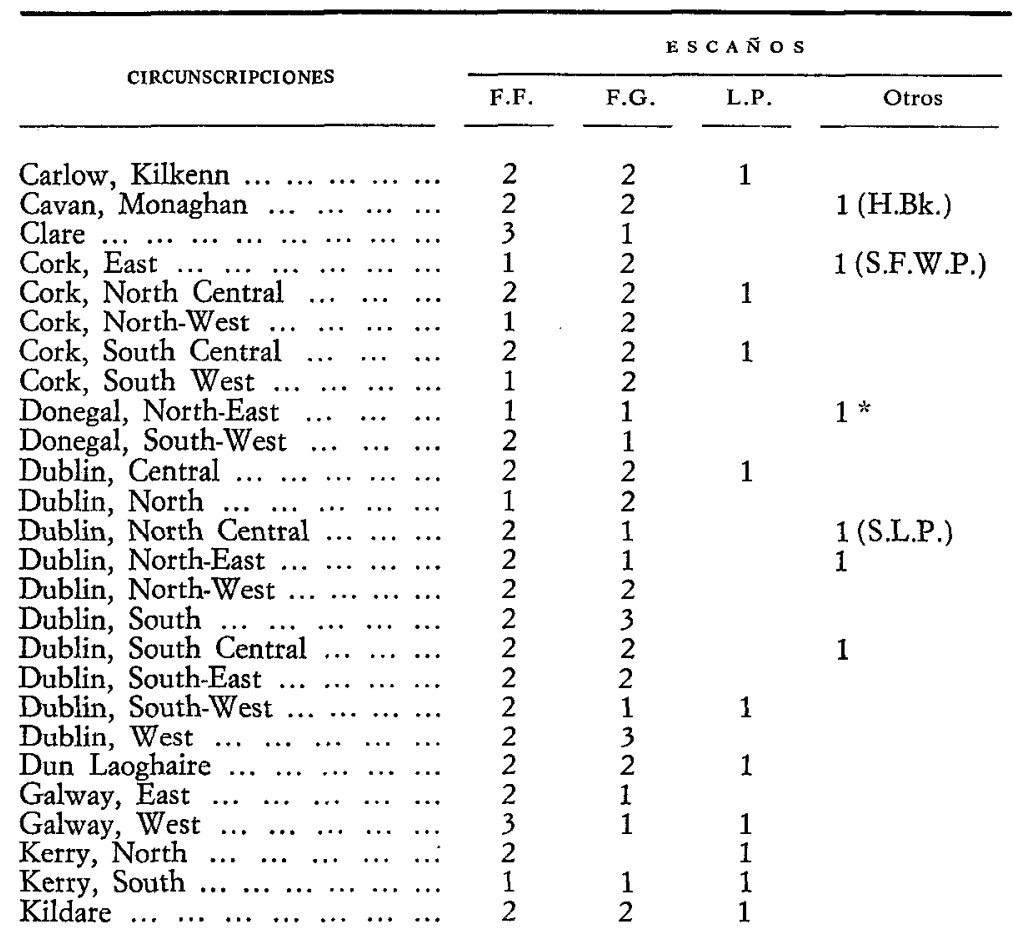




\begin{tabular}{|c|c|c|c|c|}
\hline \multirow{2}{*}{ CIRCUNSCRIPCIONES } & \multicolumn{4}{|c|}{ E S C A N OS } \\
\hline & F.F. & F.G. & L.P. & Otros \\
\hline 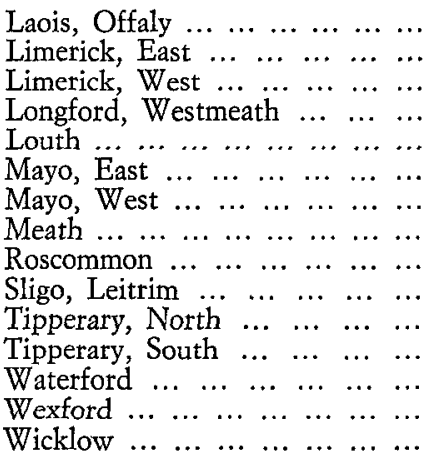 & $\begin{array}{l}3 \\
2 \\
2 \\
2 \\
2 \\
2 \\
2 \\
2 \\
2 \\
2 \\
2 \\
2 \\
2 \\
2 \\
2\end{array}$ & $\begin{array}{l}2 \\
2 \\
1 \\
2 \\
1 \\
1 \\
1 \\
2 \\
1 \\
2 \\
1 \\
1 \\
2 \\
2 \\
1\end{array}$ & $\begin{array}{r}-1 \\
1\end{array}$ & 1 (H.Bk.) \\
\hline
\end{tabular}

* Candidato independiente en las listas del F.F.

E1 sistema electoral irlandés, o de voto único transferible, constituye una combinación de la representación proporcional y el escrutinio mayoritario, de forma tal que los resultados respondan lo más fielmente a los deseos del elector. Para una mayor información sobre el sistema electoral irlandés véanse: E. Lakeman, How Democracies Vote, pág. 11 y sigs. (Faber and Faber, Londres, 1974); Jean Marie Cotteret y Claude Emeri, Les systèmes électoraux, págs. 78 a 80 (P. U. F., París, 1970). 